\title{
Optimization of Horizontal Well Fracture Parameters in Dagang Low-Permeability Oilfield
}

\author{
Yang Liu ${ }^{1, \text { a }}$, Fangfang $\mathrm{Li}^{2, \mathrm{~b}}$, Changlin Shi ${ }^{2, \mathrm{c}}$ \\ ${ }^{1}$ CNPC Dagang oilfield the fourth production plant (Gas Storage Company), 300280, Tianjin, \\ China. \\ ${ }^{2}$ CNOOC EnerTech-Drilling \& Production Co, 300452, Tianjin, China. \\ a386420439@qq.com, b413896397@qq.com, cshichl@cnooc.com.cn
}

\begin{abstract}
Horizontal well fracturing is often used in low-permeability reservoirs to increase the production of oil wells. Reasonable fracture parameters design can fully release oil flow in artificial fracture, therefore increase well productivity in horizontal wells. Take Dagang Liujianfang low permeability oil field as example, using numerical simulation methods, an ideal model was built to study fracture numbers, fracture lengths, fracture locations, and fracture types effect on horizontal well productivity. The result showed fracturing 6 fractures with $70 \mathrm{~m}$ fracture length can have higher oil recovery of the aimed oil field, besides, the factures distributed unevenly and much further than injection wells, water cut breakthrough and increase much slower.
\end{abstract}

Keywords: Horizontal well fracturing, fracture parameters, oil recovery, water cut.

\section{Introduction}

Integrated fracturing technology is an effective method to develop low-permeability oil and gas reservoirs [1]. One of the key issues to implement integrated fracturing is to optimize fracture parameters and create fracture as designed [2-3]. As far as now, integrated fracturing and fracture parameters optimization in vertical wells has been studied a lot, and some valuable achievement has been gotten [4-5]. Compared with vertical wells, horizontal wells has larger oil drainage area and higher oil production per well, therefore horizontal well fracturing technology has become an important stimulation method of low permeability oil and gas reservoirs [6-8]. For horizontal well production, due to the particularity of well pattern, it is difficult to design fracturing parameters because fracture direction, fracture length, fracture density and facture type have great effect to well productivity [9-10].

This paper take Dagang Liujianfang low permeability oil field as example, an ideal reservoir model was established and horizontal well fracture parameters were optimized by numerical simulation. The studying results can guide horizontal well fracturing implementation in field.

\section{Model information}

The Liujianfang Oilfield is a structural lithologic reservoir, and the main oil layer is Sha II and Sha III zone in Shahejie Formation. The reservoir depth is $2863.2-3756.0 \mathrm{~m}$, with original formation pressure of $45.42 \mathrm{MPa}$, saturation pressure of $12.20 \mathrm{MPa}$ and original formation temperature of 130.5 oC. The average porosity of the reservoir is $11.2 \%$, and the average permeability is $2.2 \times 10-3 \mu \mathrm{m} 2$, which belongs to extra-low porosity and low permeability reservoir. Under strong tectonics, natural structural fractures and micro-fractures developed within the reservoir.

A homogeneous mechanism model was extracted through the basic parameters of the oilfield. The basic parameters of the model include: oil layer thickness is $10.41 \mathrm{~m}$, permeability is $2.2 \times 10-3 \mu \mathrm{m} 2$, porosity is $11.2 \%, \mathrm{Kv} / \mathrm{Kh}$ is 0.5 , oil viscosity is $7.83 \mathrm{mPa} \cdot \mathrm{s}$, original formation pressure is $45.42 \mathrm{MPa}$, formation compression coefficient is $0.0005 \mathrm{MPa}-1$, initial water saturation is 0.43 . Well pattern parameters include: inversed seven-spot well pattern with six vertical injection wells and one horizontal production well, horizontal well length is $500 \mathrm{~m}$ and the well spacing is $250 \mathrm{~m}$, well injection is $160 \mathrm{~m} 3 / \mathrm{d}$. Oil and water relative permeabilities are shown in Table 1. 
Table 1. Relative Permeabilities

\begin{tabular}{ccc}
\hline Sw & Kro & Krw \\
\hline 42.57 & 1 & 0 \\
45.34 & 0.724 & 0.0224 \\
49.14 & 0.4202 & 0.0746 \\
57.08 & 0.2082 & 0.1779 \\
68.29 & 0.0409 & 0.2589 \\
72.53 & 0 & 0.2767 \\
\hline
\end{tabular}

\section{Fracture Parameters Optimize}

\subsection{Fracture Numbers.}

Keep fracture half-length $90 \mathrm{~m}$ constant, simulate horizontal fracturing well with four fractures, six fractures and 8 fractures its oil production (As shown in Figure 1). Simulate effect of fracture numbers to oil production rate, water cut and oil recovery. Figure 2 showed the simulation results. As can been from the figure, the more fractures, the higher initial oil production rate and oil recovery, but after four years, the oil production rate were almost the same. In addition, as shown in Figure 2 the more fractures, the water cut increased faster. Considering the horizontal well length is limited, and more fractures may induce water breakthrough early from injection well, it is recommend fracturing 6 fractures is best in this field.

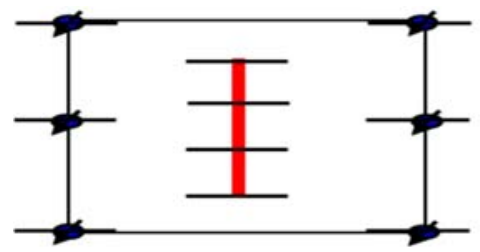

a. Four Fractures

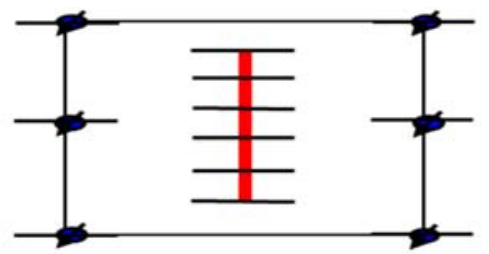

b. Six Fractures

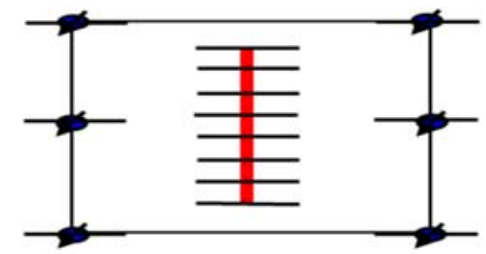

c. Eight Fractures

Fig.1 Different Fractures Numbers Diagram
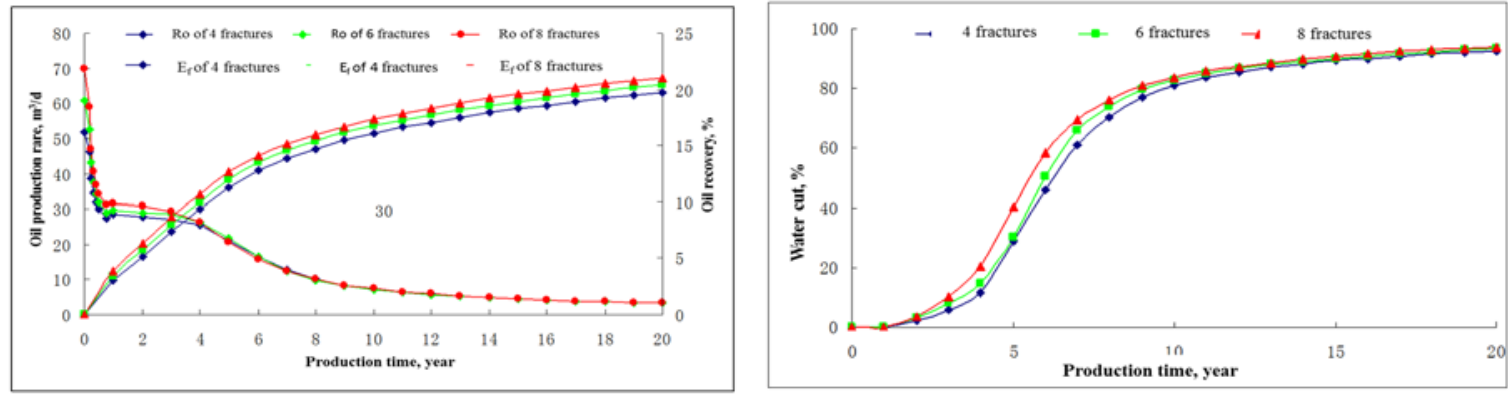

Fig.2 Oil Production Rate, Recovery and Water Cut under Different Number of Fractures

\subsection{Fracture Length.}

Keep four fractures in horizontal well and change fracture length of $50 \mathrm{~m}, 70 \mathrm{~m}, 90 \mathrm{~m}$, and $110 \mathrm{~m}$ (As shown in Figure 3), respectively. Simulate effect of fracture numbers to oil production rate, oil recovery and water cut. Figure 4 showed the simulation results. As can been from the figure, the longer the fracture length, the higher initial oil production rate but faster water cut increase (as shown in Figure 6) and lower oil recovery. When fracture length is $110 \mathrm{~m}$ and $90 \mathrm{~m}$, oil recovery almost the same. But when fracture length lower than $90 \mathrm{~m}$, oil recovery deceased greatly, and water breakthrough early. Therefore the best fracture length of hydraulic fracturing is $90 \mathrm{~m}$. 


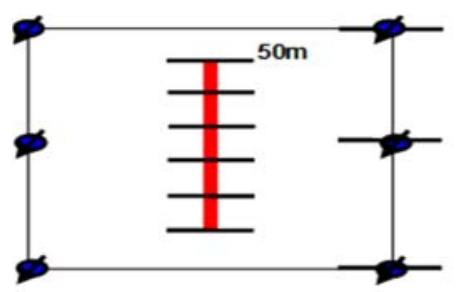

a. $50 \mathrm{~m}$ Fracture Length

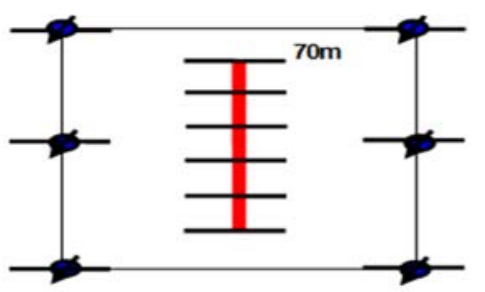

b. $70 \mathrm{~m}$ Fracture Length

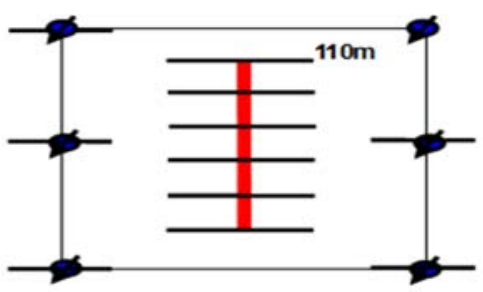

c. $110 \mathrm{~m}$ Fracture Length

Fig. 3 Different Fractures Length Diagram
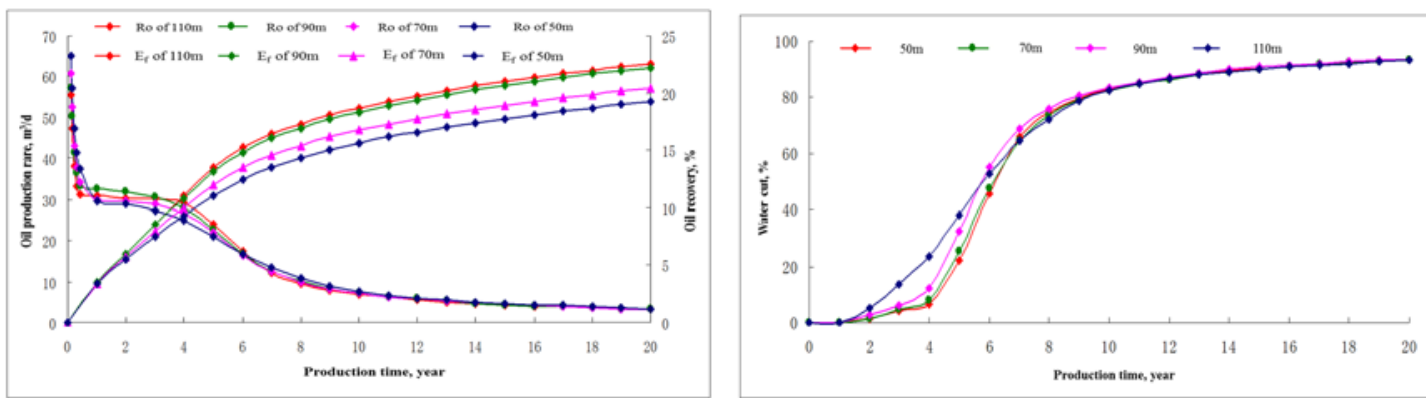

Fig.4 Oil Production Rate, Recovery and Water Cut under Different Fracture Length

\subsection{Fracture Position}

Keep fracture numbers and fracture length constant, change fracture position as shown in Figure 5. Simulate effect of fracture numbers to oil production rate, water cut and oil recovery. Figure 6 showed the simulation results. As can be seen, fractures position has very little effect on oil recovery and oil production rate. But in fracture position 3, because fractures in horizontal well were much further from middle two injection wells, water cut increased much slower. Therefore it is recommended that fracturing fractures should not be close with injection wells to avoid injection water breakthrough early and forming water channeling path.

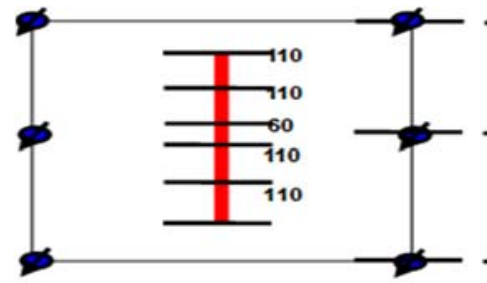

a. Fractures Position 1

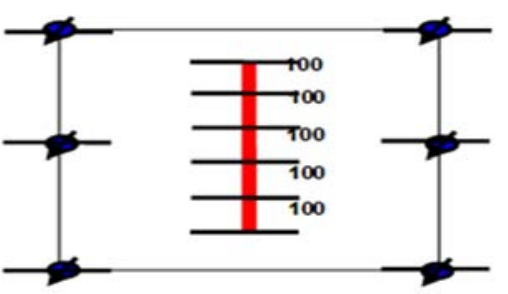

b. Fractures Position 2

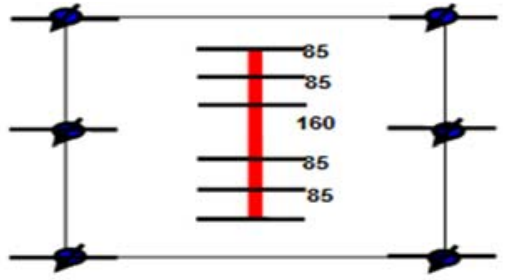

c. Fractures Position 3

Fig.5 Different Fractures Position Diagram
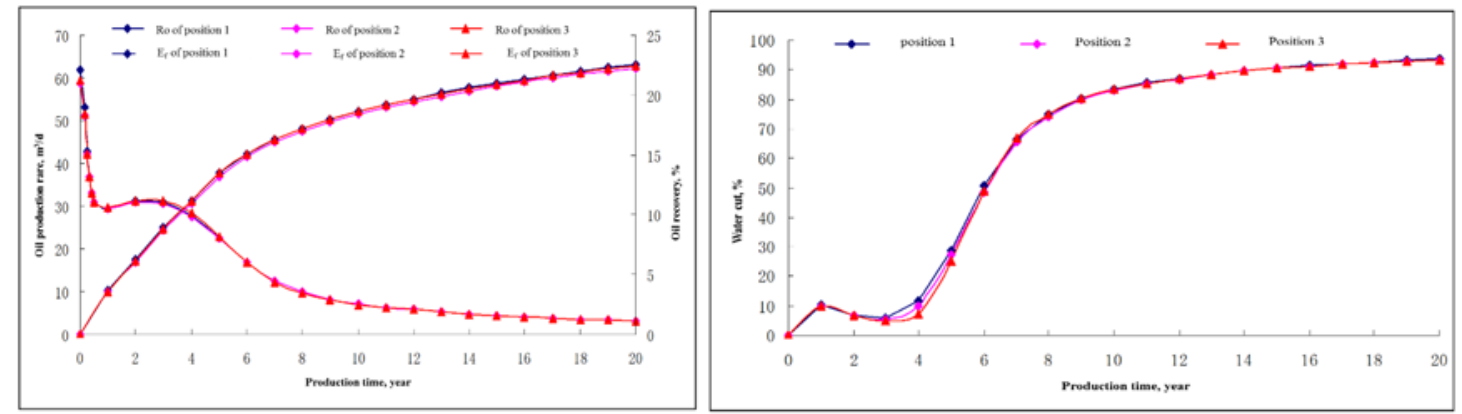

Fig.6 Oil Production Rate, Recovery and Water Cut under Different Fracture Position

\subsection{Evenly and Unevenly Fractures.}

Keep fracture numbers and total fracture length constant, change fracture distribution as shown in Figure 7. Simulate effect of fracture numbers to oil production rate, water cut and oil recovery. Figure 
8 showed simulation results. As can be seen, oil recovery and water cut of unevenly fractures are much higher than evenly fractures, and water cut increase much faster of evenly fractures. In unevenly fractures, fractures near injection wells are much shorter, so water breakthrough much slower, and oil production rate much higher. Oil recovery of unevenly fractures is $0.58 \%$ higher than evenly fractures.

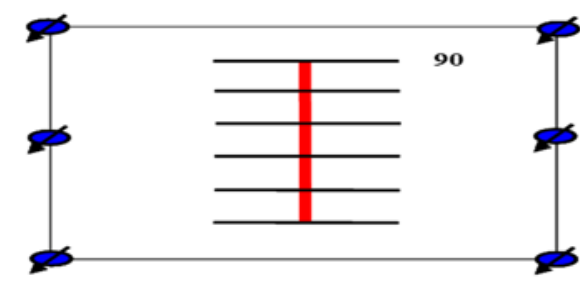

a. Evenly Fractures

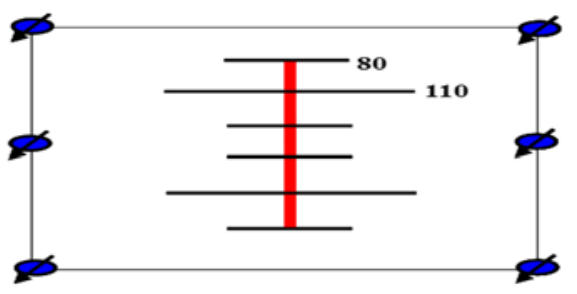

b. Unevenly Fractures

Fig.7 Different Fractures Distribution Diagram
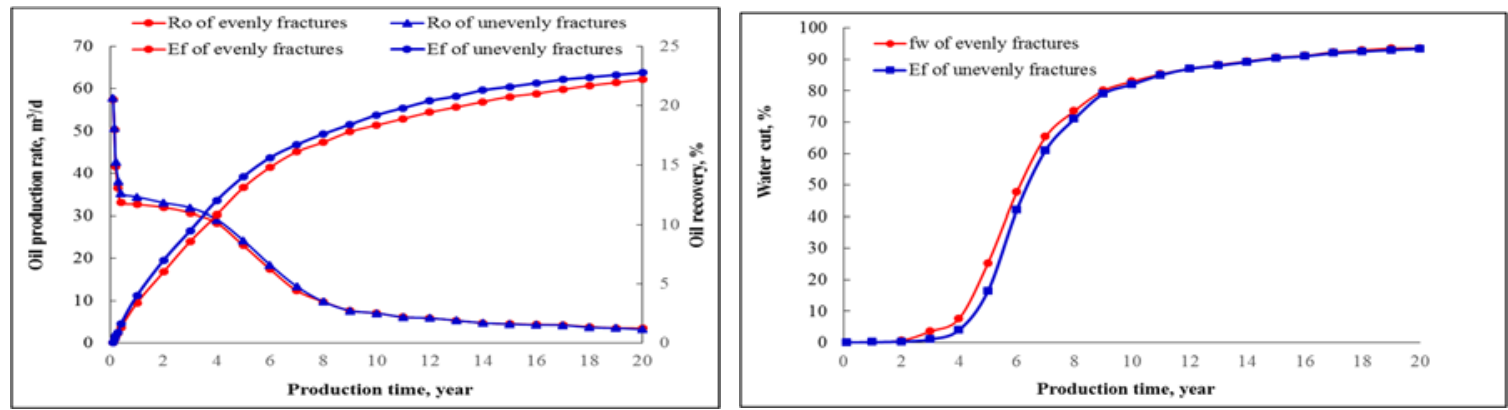

Fig.8 Oil Production Rate, Recovery and Water Cut under Different Fractures Distribution

\section{Conclusion}

Based on geological data of Dagang Liujianfang low permeability oil field, an ideal reservoir model was established to study fracture parameters to oil production rate, water cut and oil recovery. The following conclusions were obtained:

(1) For a certain reservoir, there is optimal fracture parameters to stimulate the wells production. For Dagang Liujianfang oil field, the best fracture parameters are as follows: fracture number is six, fracture length is $70 \mathrm{~m}$, fractures distributed further from injection wells and fractures near injection well shorter can have higher oil recovery and slower water cut increase.

(2) For horizontal well integrated fracturing, the effects of fractures at toe and at heel on productivity is greater than fractures in the intermediate. During fracturing, the length of intermediate fractures can be reduced to save fracturing cost.

(3) By analyzing the influence of fracture parameters on horizontal well productivity, the influence degree from large to small is fracture length, fracture number and fracture distribution.

\section{References}

[1]. Conway, M. W. and Harris, L. E. A Laboratory and Field Evaluation of a Technique for Hydraulic Fracturing Stimulation of Deep Wells. Paper SPE 10964 presented at the 57th Annual Technical Conference and Exhibition, New- Orleans, Sept.26-29, 1982.

[2]. Ma Xinfang, Fan Fengling, Zhang Shouliang. Fracture Parameters Optimization of Horizontal Wells in Low Permeability Gas Reservoirs [J]. Natural Gas Industry, 2005, 25(9): 61-63.

[3]. Le H V, Kesavan S, Dawson J C, et al. Compositions and Methods for Hydraulic Fracturing: US, US 6169058 B1 [P]. 2001.

[4]. Nordgren R P. Propagation of a Vertical Hydraulic Fracture [J]. Society of Petroleum Engineers Journal, 1972, 12(4):306-314. 
[5]. Soliman M Y, Hunt J L, Rabaa A M E. Fracturing Aspects of Horizontal Wells [J]. Journal of Petroleum Technology, 1990, 42(8): 966-973.

[6]. Wang Jijun, Guo Ping, Wang Delong, et al. Fractures Parameters Optimization of Horizontal Well Fracturing Based on PEBI Grid [J].Natural Gas and Oil, 2013, 31(1): 57-59.

[7]. Yuan Shuai, Li Chunlan, Zeng Baoquan, et al. Optimization of Horizontal Well Fracture parameters [J]. Petroleum Drilling Techniques, 2010, 38(4): 99-103.

[8]. Roussel N P, Sharma M M. Optimizing Fracture Spacing and Sequencing in Horizontal-Well Fracturing [J]. SPE Production \& Operations, 2011, 26(2):173-184.

[9]. Wang Jijun, Guo Ping, Wang Delong, et al. Fractures Parameters Optimization of Horizontal well fracturing based on PEBI grid [J].Natural Gas and Oil, 2013, 31(1): 57-59.

[10]. Qu Zhanqing, Zhao Yingjie, Wen Qingzhi, et al. Optimal Design of Fracture Parameters for Horizontal Fracturing [J].Petroleum Geology and Recovery Efficiency, 2012, 19(4): 106-110. 